\title{
Microstructure Evolution at Different Cooling Rates of Low Carbon Microalloyed Steels
}

\author{
Elena Brandaleze ${ }^{1}$, Matías Ramírez ${ }^{1}$ and Martina Avalos ${ }^{2}$ \\ 1. Metallurgy Department and Deytema Centre, Universidad Tecnológica Nacional, Facultad Regional San Nicolás, Colón 332 , \\ 2900 San Nicolás, Argentina \\ 2. IFIR-Conicet, Universidad Nacional de Rosario, Ocampo y Esmeralda,Ocampo 210 bis, 2000 Rosario, Argentina
}

\begin{abstract}
In low carbon microalloyed steels $(\mathrm{C}<0.1 \%)$, the content of $\mathrm{V}, \mathrm{Nb}$ and Ti affects the phases transformation kinetic during cooling in the rolling process. The final microstructure determines the required mechanical properties such as high formability, high toughness and adequate strength. For this reason it is relevant to identify and determine the volume fraction of the ferrite, bainite and martensite present in the structure. The microalloying elements: $\mathrm{V}, \mathrm{Nb}$ and $\mathrm{Ti}$ promote carbides precipitation during cooling. The precipitates control the grain size refinement during hot rolling process and the mechanical properties of the steel. In this sense it is necessary to increase the knowledge on the microstructure evolution at different cooling rates. In this paper, the results obtained on two low carbon microalloyed steels (with $\mathrm{C}$ contents between $0.11 \%-0.06 \%$ ) are reported. An integrated methodology including dilatometry in combination with microscopy techniques was applied. By EBSD (Electron Backscatter Diffraction) technique and microhardness measurements, the structural study was completed. Through a thermodynamic simulation using Fact Sage the type of precipitates in the studied steels structure at the temperature range between $950{ }^{\circ} \mathrm{C}$ and $450{ }^{\circ} \mathrm{C}$, were predicted. The information on the evolution of the steel structure at rolling process conditions is relevant to consider changes in processing conditions.
\end{abstract}

Key words: Low carbon steels, dilatometry, cooling curves, phases transformation, precipitates.

\section{Introduction}

The steel for automotive applications constitutes a topic of high interest in the current metallurgy. Modern vehicle production introduces new competing requirements, which includes the production of mass efficient automobile bodies. High strength steel sheets can significantly help reducing vehicle weight when the design and fabrication route are optimized and adapted to the selected material [1]. The requirements about mechanical properties are focused in high strength combined with high toughness or high formability. These mechanical properties are achieved through an appropriate kinetic of precipitation and a precisely ratio of specific microconstituents. For this reason it is relevant to revise and increase the knowledge about $\gamma \rightarrow \alpha$ transformation and

Corresponding author: Elena Brandaleze, professor/Ph.D., research field: metallurgy and materials science. precipitation at forming process conditions. The characterization and quantification of the different types of ferrite in steels is of great importance in materials engineering. The proportion and distribution of microconstituents strongly influences the steel behaviour [2]. It is well known that other microstructural aspects like the grain size refinement produce increments in strength and toughness [3].

In this paper two low carbon microalloyed steels, with $0.06 \% \mathrm{C}$ and $0.11 \% \mathrm{C}$, were selected. Both steels contain microalloy elements such as: $\mathrm{Nb}, \mathrm{V}$ and $\mathrm{Ti}$ in different contents. The carbide precipitates (or nano precipitates) promote: a) the interstitial $\mathrm{C}$ removal from the matrix; b) modification on the $\gamma \rightarrow \alpha$ transformation kinetic; c) promotion of grain refinement; and d) control of crystallographic texture. The different types of carbides that could be formed in the structure include $\mathrm{M}_{23} \mathrm{C}_{6}$ and $\mathrm{MX}(\mathrm{M}=\mathrm{Nb}, \mathrm{V}, \mathrm{Ti}$ and $\mathrm{X}=\mathrm{C}$ and/or N) [4]. 
To detect the phase transformation temperatures, dilatometry tests are performed in these materials, as it is frequently used to study phase transformation temperatures of different steel grades $[5,6]$. In particular, in this work the samples of both steels were tested from austenite phase field at the maximum heating temperature of $950{ }^{\circ} \mathrm{C}$ and different cooling rates between $0.03{ }^{\circ} \mathrm{C} / \mathrm{s}-8.21{ }^{\circ} \mathrm{C} / \mathrm{s}$ accordingly to industry requirements. The $\gamma \rightarrow \alpha$ transformation temperatures, including bainitic transformation temperatures are determined using $\quad \mathrm{L} / \mathrm{L}_{0}(\%)-\mathrm{T}\left({ }^{\circ} \mathrm{C}\right)$ curves. To construct the CCT (Continuous Cooling Transformation curves) curves it is necessary to correlate the dilatometry results with information associated with the structure and microhardness measurements.

The microstructure of the samples was characterized by optical microscopy and scanning electron microscopy. The phases were identified and quantified using EBSD (Electron Backscatter Diffraction). Microhardness was also measured on each sample and the CCT were obtained.

Different authors use thermodynamic simulation tools in order to predict metal carbide phases in steels at different temperature conditions [7, 9]. In this work the stability and transformation behaviour of complex carbides during thermomechanical processing were established by using Fact Sage at forming processing temperatures. Results are useful to predict the type of carbides $(\mathrm{Nb}, \mathrm{Ti}$ and $\mathrm{V})$, in the structure of both steels. The information presented in this work is a contribution for industry to adjust the forming processing conditions.

\section{Experimental Section}

The content of carbon and of microalloy elements of the steels selected is detailed in Table 1 .

Samples of both steels were dimensioned at $5 \mathrm{~mm} \times$ $5 \mathrm{~mm} \times 25 \mathrm{~mm}$ and tested in a THETA DILATRONICS II dilatometer. The maximum heating temperature was $950{ }^{\circ} \mathrm{C}$ with a heating rate of $10{ }^{\circ} \mathrm{C} / \mathrm{min}$ in $\mathrm{Ar}$
Table 1 Carbon and microalloy elements contents in (wt. \%) of the steels.

\begin{tabular}{lllll}
\hline Steel & $\mathrm{C}$ & $\mathrm{Ti}$ & $\mathrm{Nb}$ & $\mathrm{V}$ \\
\hline $\mathrm{A}$ & 0.06 & 0.04 & 0.10 & - \\
$\mathrm{B}$ & 0.11 & 0.01 & 0.05 & 0.09 \\
\hline
\end{tabular}

atmosphere and holding time of $8 \mathrm{~min}$. Finally different cooling rates between $0.034{ }^{\circ} \mathrm{C} / \mathrm{s}$ and $8.21{ }^{\circ} \mathrm{C} / \mathrm{s}$ were applied.

By the dilatometric curves the different transformation temperatures were identified at each cooling rate for both steels and the $\mathrm{T}\left({ }^{\circ} \mathrm{C}\right)-\mathrm{t}(\mathrm{s})$ diagram was constructed for each steel. The results were correlated with the structure through a characterization that includes: grain size, volume fraction of the present phases and microhardness.

The optical microscopy observations were made using a light microscope Olympus GX51 with a LECO IA 32 image analysis system. The samples were polished with $\mathrm{SiC}$ from 320 to 1,000 grit and diamond paste from $6 \mu \mathrm{m}$ to $1 \mu \mathrm{m}$ and the final polishing was $\mathrm{Al}_{2} \mathrm{O}_{3}$ of $0.03 \mu \mathrm{m}$ in Vibromet vibratory polisher. Le Pera selective metallographic etchant was applied to identify presence of bainite and quantify the volume fraction using the colorimetric method.

OIM (Orientation images microscopy) maps were constructed from data collected by EBSD scans performed in a field emission gun FEI Quanta 200 scanning electron microscope, operated at $20 \mathrm{kV}$ equipped with an EDAX - TSL OIM + EDAX - EDS system. The EBSD scans were collected from samples tested by dilatometry and mounted in an edge retention conductive resin. The samples were mechanically polished by using diamond pastes of 9,6 , 3 and $1 \mu \mathrm{m}$. The process was finished using $0.05 \mu \mathrm{m}$ colloidal silica for $10 \mathrm{~min}$. Two types of areas were explored: one of them of $100 \mu \mathrm{m} \times 100 \mu \mathrm{m}$, step sizes of 0.15 to evaluate percentage of phases and the others of up to $15 \mu \mathrm{m} \times 15 \mu \mathrm{m}$ and step size of $0.07-0.03$ for detail examination of the microstructure. The uncertainty of the orientation measurements does not exceed $0.5^{\circ}$. The analysis of the data was carried out 
with the software OIM of EDAX.

Microhardness measurements were performed in a LECO LMT 300 working with a load of $10 \mathrm{gf}$ and equipped with Vickers indenter. The thermodynamic simulation of the precipitation process was performed by FACT SAGE 7.0, using the equilibrium module and the data bases: FSstel and Misc. The temperature conditions considered are in the range between $950{ }^{\circ} \mathrm{C}$ to $450{ }^{\circ} \mathrm{C}$.

\section{Results and Discussion}

The requirements of high strength and elongation are continuously increasing. As a consequence, displacive transformations, such as bainite and martensite, have been discussed in detail along the last years [6].

\subsection{Transformations Study by Dilatometry}

While in a single-phase region the thermal expansion coefficient is a function of temperature, in a multiphase region it depends not only on the temperature change but also of the volume and relative amounts of phases because of the development of new phases with different specific volumes [10].

To determine the phase transformation temperatures for the steels the slope changes identified on the expansion curves, $\quad \mathrm{L} / \mathrm{L}_{0}(\%)-\mathrm{T}\left({ }^{\circ} \mathrm{C}\right)$ were calculated for steel $\mathrm{A}(0.06 \% \mathrm{C})$ and $\mathrm{B}(0.1 \% \mathrm{C})$ and the corresponding curves of continuous cooling at $0.03{ }^{\circ} \mathrm{C} / \mathrm{s}, 0.23{ }^{\circ} \mathrm{C} / \mathrm{s}, 3.28{ }^{\circ} \mathrm{C} / \mathrm{s}$ and $8.21{ }^{\circ} \mathrm{C} / \mathrm{s}$ were plotted. The transformation temperatures obtained were placed on each cooling rate curve. The diagrams for both steels are reported in Figs. 1 and 2 .

From the comparison between the continuous cooling curves of both steels is evident that the higher content of $\mathrm{C}$ and microalloying elements in the steel $\mathrm{B}$, promotes a downward and slightly to the right displacement of the transformation curves $[11,12]$.

The CCT curves show that the $\gamma \rightarrow \alpha$ transformation is higher than $750{ }^{\circ} \mathrm{C}$ and the bainite transformation temperatures are around $690^{\circ} \mathrm{C}$ for both $\mathrm{A}$ and B steels. These temperatures are consistent with the informed by Wilson [13]. However, to corroborate the CCT diagrams it is necessary to identify the phases through a structural study.

\subsection{Structural Study}

Optical microscopy observations allow to identify in the samples etched with Le Pera reagent two different phase types: FP (polygonal ferrite) and B (bainite) in different amounts. The volume fraction of bainite and

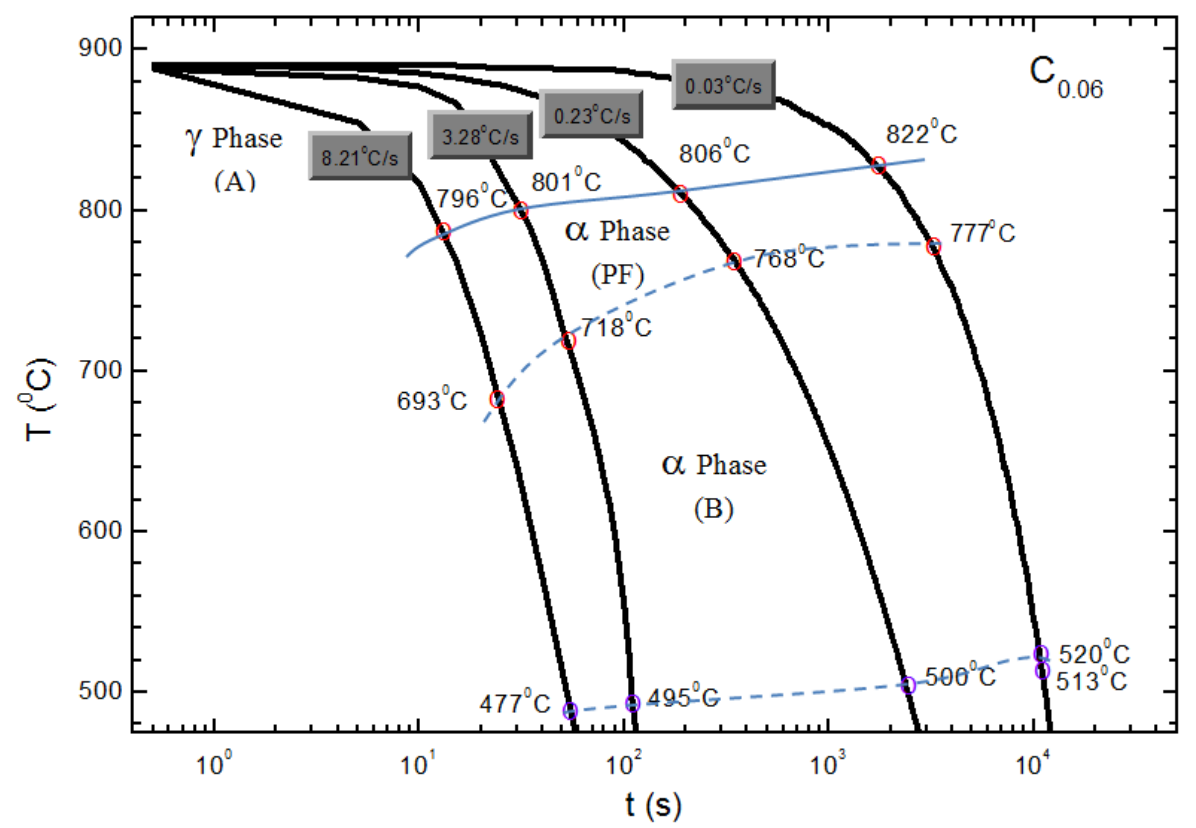

Fig. 1 CCT curve constructed for the steel A. 


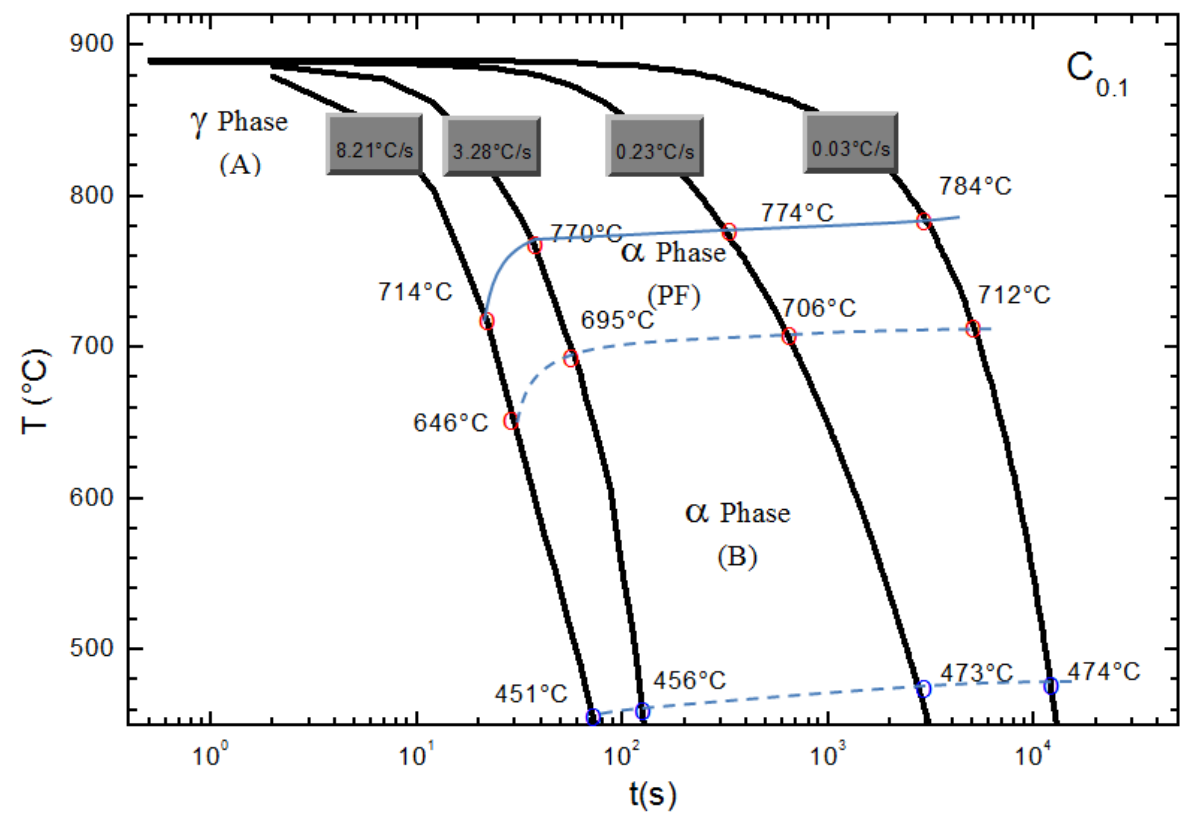

Fig. 2 CCT curve constructed for the steel B.

Table 2 Structure results obtained by optical microscopy.

\begin{tabular}{lllll}
\hline Steel & Cooling rate & $\begin{array}{l}\text { Grain size } \\
(\mu \mathrm{m})\end{array}$ & Bainite (\%) & Phases \\
\hline \multirow{3}{*}{$\mathrm{A}$} & High & $<2$ & 3 & $\mathrm{FP}+\mathrm{B}$ \\
& Intermediate & $<2$ & 1.2 & $\mathrm{FP}$ \\
& Low & 4 & - & $\mathrm{FP}$ \\
\hline \multirow{3}{*}{$\mathrm{B}$} & High & $<3$ & 12 & $\mathrm{FP}+\mathrm{B}$ \\
& Intermediate & 3 & 5.6 & $\mathrm{FP}+\mathrm{B}$ \\
& Low & 3 & - & $\mathrm{FP}$ \\
\hline
\end{tabular}

the grain size in each sample at different cooling rates were determined by image analysis. In Table 2 the results for representative cooling rates are presented: $8.21{ }^{\circ} \mathrm{C} / \mathrm{s}$ for high, $3.28^{\circ} \mathrm{C} / \mathrm{s}$ for intermediate and low cooling rates $\left(0.23^{\circ} \mathrm{C} / \mathrm{s}\right.$ and $\left.0.03{ }^{\circ} \mathrm{C} / \mathrm{s}\right)$.

The optical microscopy results show that at low cooling rates the structure of both steels is constituted by $\mathrm{PF}$. In the steel $\mathrm{B}$, at intermediate cooling rate, the structure is composed by traces of bainite in PF matrix. However, at the same cooling rate, the structure of the steel A only reveals the presence of PF as the main phase. At $8.21{ }^{\circ} \mathrm{C} / \mathrm{s}$, the structure of both steels presents different amounts of bainite in a matrix of PF: $3 \%$ and $12 \%$ in steels $\mathrm{A}$ and $\mathrm{B}$, respectively.

The final grain size in the A and B steels at $8.21^{\circ} \mathrm{C} / \mathrm{s}$ is $<2 \mu \mathrm{m}$ for A steel and $<3 \mu \mathrm{m}$ for steel $\mathrm{B}$.

For inspecting in more details the crystallographic microstructure, the EBSD technique was applied. The main problem about current phase identification is the similitude in crystal structure: polygonal ferrite and bainite are both bcc structures. In this work, a combination of three different criteria was applied on the analysis:

(a) Although bainite and ferrite have a bcc crystalline structure, the different amounts of defects in the structure is useful to discriminate between both phases using IQ maps. Two areas with different IQ are clearly distinguished in the maps: the one with lower IQ corresponds to bainite and the other corresponds to ferrite.

(b) Another elements might be considered to characterize and quantify the phases in these steels like grain boundaries, aspect ratio, mean misorientation and grain size [14].

(c) The GAM (Grain Average Missorientation) parameter for polygonal ferrite and bainite might be useful.

$\mathrm{Su}$ et al. [15] reported the application of a similar methodology to study TRIP steels. In this paper, the EBSD let to identifying different ferrite phases (bcc) present in low carbon microalloyed steel structure: a main phase of polygonal ferrite (bcc) which presents 
very low missorientation and two different types of structures at the triple points, one compatible with $\mathrm{CB}$ (columnar bainite) and the other consistent with $\mathrm{AB}$ (acicular bainite). The $\mathrm{CB}$ phase, presents misorientations slightly higher than PF $\left(\sim 3^{\circ}\right)$. Meanwhile, the $\mathrm{AB}$ presents the lower IQ and misorientations between $50^{\circ}-60^{\circ}$. Gao et al. [16], working with steels with bainitic structures, reported the presence of a bainite phase with lath interfaces similar to the morphology of the martensite, as it was identified by SEM and TEM. The authors also reported misorientations between $50^{\circ}-60^{\circ}$ similar to the measured misorientation reported in this paper for the $\mathrm{AB}$ phase. EBSD provides a more detailed and new information about the characteristics of the continuous cooling transformation phases in steels, such as $\mathrm{CB}$ and $\mathrm{AB}$ and $\mathrm{PF}$. For summarizing, grain size, bainite volume fraction and the different types of phases identified by EBSD in the samples at high, intermediate and low cooling rates, are detailed in Table 3.

Fig. 3 shows a detailed IQ + GAM map obtained in a triple point of steel B sample cooled at $8.21{ }^{\circ} \mathrm{C} / \mathrm{s}$ with different types of bainite. It is possible to observe: $\mathrm{PF}$ (polygonal ferrite) (green), CB (columnar bainite) (yellow), and $\mathrm{AB}$ (acicular bainite) with plates in different colours indicating different degrees of misorientations inside the plates. The fine ferrite platelets increase toughness. The missorientation angle between neighbouring platelets is greater than $45^{\circ}$, in coincidence with Gourgues et al. [17].

At lower cooling rates, only $\mathrm{PF}$ grains nucleate at prior austenite grain boundaries of both steels. However, at higher cooling rates, the larger driving force induces the formation of bainite with different orientations, including fine blocks of $\mathrm{AB}$ [15].

The very fine grain size $(\varnothing<4 \mu \mathrm{m})$ was corroborated in steels A and B. It is relevant to consider that both low carbon microalloyed steels achieved a very fine grain size together with a good percentage of microconstituents at the current cooling
Table 3 Structure results obtained by EBSD.

\begin{tabular}{lllll}
\hline Steel & Cooling rate & $\begin{array}{l}\text { Grain size } \\
(\mu \mathrm{m})\end{array}$ & $\begin{array}{l}\text { Bainite } \\
(\%)\end{array}$ & Phases \\
\hline \multirow{3}{*}{$\mathrm{A}$} & High & 2 & 3 & $\mathrm{FP}+\mathrm{BC}+\mathrm{BA}$ \\
& Intermediate & 2 & 2 & $\mathrm{FP}+\mathrm{BC}$ \\
& Low & 4 & - & $\mathrm{FP}$ \\
$\mathrm{B}$ & High & 2 & 10 & $\mathrm{FP}+\mathrm{BC}+\mathrm{BA}$ \\
& Intermediate & 3 & 6 & $\mathrm{FP}+\mathrm{BC}$ \\
& Low & 3 & - & $\mathrm{FP}$ \\
\hline
\end{tabular}

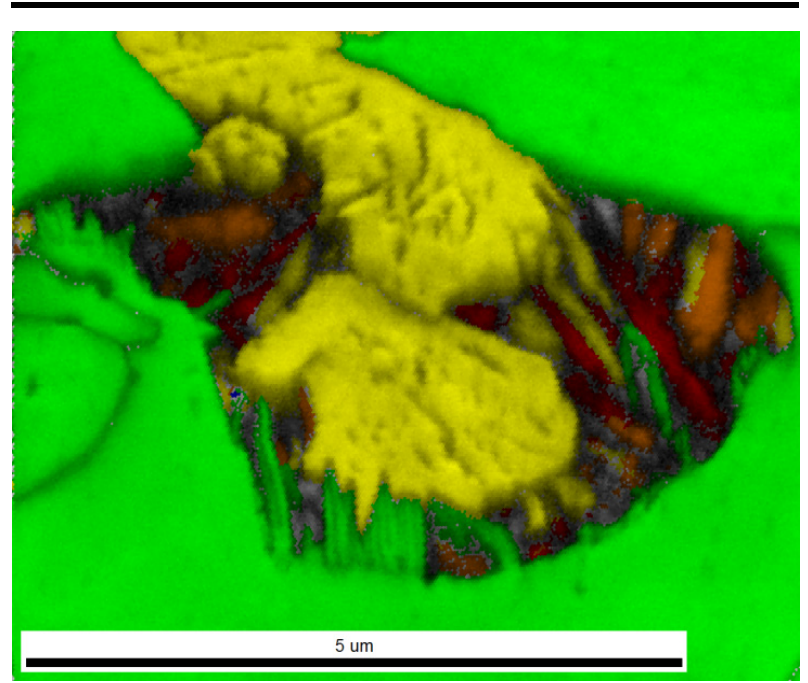

Fig. 3 Grain Average GAM map of bainite phase in sample of $B$ steel cooled at $8.21^{\circ} \mathrm{C} / \mathrm{s}$.

rates, in agreement with new steel technology requirements [3].

\subsection{Thermodynamic Simulation of the Precipitation} Process

In microalloyed steels there are different mechanisms that contribute to increaseing the strength. One of them is the precipitation from a single phase solid solution. The addition of $\mathrm{Nb}$, Ti and $\mathrm{V}$ promotes the formation of fine strengthening precipitates, mainly in $\gamma$ phase. The small discrete carbides are very hard and produce a large bowing of the dislocations $[3,8]$. Also the addition of microalloying elements could induce grain refinement that constitutes other strengthening mechanism and allows to achieve a superior toughness [3].

In this paper, results of the precipitation process obtained by thermodynamic simulation applying the software Fact Sage on steels A and B are informed. For 
the current simulation, the temperature range for simulation was between $950{ }^{\circ} \mathrm{C}-450{ }^{\circ} \mathrm{C}$.

In A steel, the stability and precipitation of the $\mathrm{Ti}$ and $\mathrm{Nb}$ carbides (type $\mathrm{MX}, \mathrm{fcc}$ ), are predicted from $950{ }^{\circ} \mathrm{C}$ ( $\gamma$ phase). The estimated proportion of $\mathrm{NbC}$ in the steel structure is higher than TiC. The result is consistent with the higher content of $\mathrm{Nb}$ as it was reported in the chemical composition of the steel. At $\gamma \rightarrow \alpha$ transformation a slight decrease of the precipitation process is predicted. The crystalline structure evolution from $\gamma$ (fcc) to $\alpha$ (bcc), affects $\mathrm{NbC}$ and TiC precipitation in a similar way. Also, a dramatic decrease of both precipitates content in the structure are estimated at $\sim 750{ }^{\circ} \mathrm{C}$, in coincidence with the bainitic transformation start temperature for the steel A. The simulation also predicts precipitates such as $\mathrm{M}_{7} \mathrm{C}_{3}, \mathrm{M}_{5} \mathrm{C}_{2}$ and $\mathrm{M}_{23} \mathrm{C}_{6}$ in the structure of the steel $\mathrm{A}$.

The B steel, with higher content of carbon $(0.1 \% \mathrm{C})$ and three microalloying elements $(\mathrm{Nb}$, Ti and $\mathrm{V})$, is susceptible to a more significant precipitation on the structure. Two types of $\mathrm{V}$ carbides are predicted in the structure: $\mathrm{V}_{7} \mathrm{C}_{3}$ and $\mathrm{VC}$. The $\mathrm{V}_{7} \mathrm{C}_{3}$ precipitation starts at $\sim 850{ }^{\circ} \mathrm{C}$ in $\gamma$ phase and continues during $\gamma \rightarrow \alpha$ transformation. However, the amount of this precipitate in the structure is very low. The main precipitate of $\mathrm{V}$ in the structure is cubic $\mathrm{VC}$ (fcc) that starts to precipitate in $\gamma$ phase. During $\gamma \rightarrow \alpha$ transformation, the amount of $\mathrm{VC}$ precipitate decreases, showing the impact of the crystalline structure evolution on the precipitation kinetic. At lower temperatures, in $\alpha$ phase the polygonal ferrite and the bainitic phases promote the $\mathrm{VC}$ precipitation again. Takeda et al. [18] informed that the VC (fcc) has a strongly ionic character bonds, a high cohesive energy and consists on cubic single crystals that promotes strength. In addition, considerable amount of $\mathrm{TiC}(\mathrm{fcc})$ and $\mathrm{NbC}$ (fcc) precipitates are predicted in the steel $\mathrm{B}$ at $950^{\circ} \mathrm{C}$. Both carbides show a higher precipitation tendency in $\gamma$ phase and at lower temperatures in bainitic phases. The polygonal ferrite limits the $\mathrm{TiC}$ and $\mathrm{NbC}$ precipitation tendency.

The first effect of the $\mathrm{NbC}$ presence is the grain-boundary pinning in austenitic state, leading to a refined grain size and the resulting mechanical properties.

\subsection{Microhardness Measurements}

Microhardness measurements were carried out to analyse the impact of the structure evolution on the mechanical properties in both steels A and B. Fig. 4

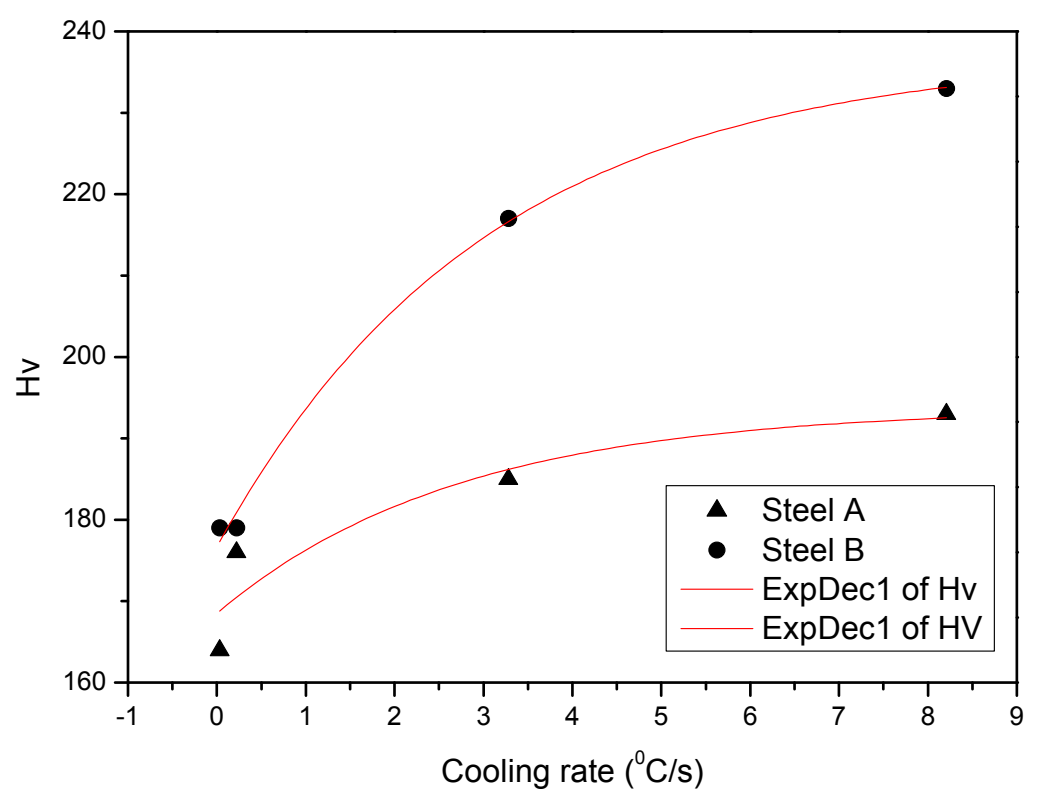

Fig. 4 Microhardness results obtained in the steels $\mathrm{A}$ and B samples, cooled at different cooling rates. 
shows that the steel B developed a structure with higher microhardness than the steel $\mathrm{A}$ with lower $\mathrm{C}$ and microalloying element amounts. The results are also justified by the important precipitation and higher proportions of bainitic phases at intermediate and higher cooling rates.

It is relevant to remark that B steel also contains precipitates of VC (fcc) which contribute to intensifying the strength [17].

\section{Conclusions}

The dilatometry tests integrated with a structural study allow obtaining relevant information on the $\gamma \rightarrow \alpha$ transformation and the phase evolution for low carbon microalloyed steels under continuously cooling conditions. However, for very fine grain size steels $(\varnothing$ $<4 \mu \mathrm{m}$ ), it is necessary to combine optical metallography with EBSD technique an exhaustive characterization of the microstructure.

By EBSD, it was possible to identify and characterize three different types of ferrite (bcc) in the steels at high cooling rates: Polygonal Ferrite as the main matrix phase, and two other phases, compatibles with bainite, columnar and acicular. It was observed that the bainitic phases were nucleated in triple points of the polygonal ferrite, probably favoured by a lower grain size of the matrix.

The main difference observed between both steels, at the same intermediate or high cooling rates, is related with the amount of bainitic phases. The results are in concordance with the partial CCT curves obtained and the chemical composition of the steels.

The thermodynamic simulation study allows predicting the possible types of precipitates at the considered cooling conditions. The ultrafine particles would require transmission electron microscopy for visualization. However, the information obtained by simulation is very useful to improve industry-processing conditions to achieve the control of the final grain size and good mechanical behaviour.

\section{Acknowledgment}

The authors thank Dr. Raul Bolmaro for valuable discussion. This work was founded by Universidad Tecnológica Nacional. The authors acknowledge the facilities and the scientific and technical assistance of the Electron Microscopy Laboratory of CCT Conicet Rosario. The authors thank Vanina Tartalini and Pablo Risso for the technical assistance.

\section{References}

[1] Beynon, N. D., Oliver, S., Jones, T. B., and Fourlaris, G. 2005. "Tensile and Work Hardening Properties of Low Carbon Dual Phase Strip Steels at High Strain Rates." Materials Science and Technology 21 (7): 771-8.

[2] Shresta, S. L., Breen, A. J., Trimby, P., and Proust, G. 2014. "An Automated Method of Quantifying Ferrite Microstructures Using Electron Backscatter Diffraction (EBSD) Data." Ultramicroscopy 137: 40-7.

[3] Howe A. A. 2009. "Industry Perspective on Ultrafine Grained Steels." Materials Science and Technology 25 (7): 817-9.

[4] Tamura, M., Ikeda, K., Esaka, H., and Shinozuka, K. 2001. "Precipitation Behavior of $\mathrm{NbC}$ in $9 \% \mathrm{Cr} 1 \% \mathrm{Mo} 0.2 \% \mathrm{VNb}$ Steel." ISIJ International 41 (8): 908-14.

[5] Kim, S. I., Baek, D. J., Lee, Y., and Choi, S. H. 2005. "Influence of Boron on Dynamic Recrystallization and Continuous Cooling Transformation of High Strength Interstitial Free Steels." Materials Science Forum 500: 321-8.

[6] Mangai, A., Biswas, P., Lenka, S., Singh, V., Singh, S. B., and Kundu, S. 2014. "Dilatometric and Microstructural Response of Variant Selection during $\alpha$ ' Transformation." Materials Science and Technology 30 (9): 1116-24.

[7] Danon, C. A., and Servant, C. 2005. "Thermodynamic Modeling in Reduced Activation Steels." ISIJ International 45 (6): 903-12.

[8] Servant, C., and Danon, C. A. 2004. "CALPHAD Modelling of the Unmixing of Transition Metal Carbide Phases." Computer Coupling of Phase Diagrams and Thermochemistry 28: 337-53.

[9] Chen, J., Li, F., Liu, Z. Y., Tang, S., and Wang, G. D. 2013. "Influence of Deformation Temperature on $\gamma \rightarrow \alpha$. Phase Transformation in Nb-Ti Microalloyed Steel during Continuous Cooling." ISIJ International 53 (6): 1070-5.

[10] Boyadjiev, I. I., Thomson, P. F., and Lam, Y. C. 1996. "Computation of the Diffusional Transformation of Continuously Cooled Austenite for Predicting the Coefficient of Thermal Expansion in the Numerical 
Analysis of Thermal Stress." ISIJ International 38 (11): 1413-9.

[11] Badheshia, H. K. D. H. 2001. Bainite in Steels. 2nd ed. Cambridge, UK: The University Press.

[12] Yan, P., and Badheshia, H. K. D. H. 2015. "The Austenite-ferrite Transformation in Enhanced-niobium Low Carbon Steel." Materials Science and Technology 31: 1066-76.

[13] Wilson, E. A. 1984. "The $\gamma \rightarrow \alpha$ Transformation in Low Carbon Irons." ISIJ International 34 (8): 615-30.

[14] Shrestha, S. L., Breen, A. J., Trimby, P., Proust, G., Ringer, S. P., and Carney, J. M. 2014. "An Automated Method of Quatifying Ferrite Microsctructures Using EBSD (Electron Backscatter Diffraction) Data." Ultramicroscopy 137: 40-7.

[15] Su, B., Lin, H. P., Kuo, J. C., and Pan, Y. T. 2014. "EBSD
Investigation on Microstructure Transformation in Low Carbon Steel during Continuous Cooling." Canadian Metallurgical Quarterly 53 (3): 353-9.

[16] Gao, G. H, Zhang, H., and Bai, B. Z. 2012. "Improved Properties of Mn Series Ultralow Carbon Steel with Ultrafine Bainitic Structure." Materials Science and Technology 28 (7): 767-4.

[17] Gourgues, A. F., Flower, H. M., and Lindley, T. C. 2000. "Electron Backscattering Diffraction Study of Acicular Ferrite, Bainite and Martensite Steel Microsctructure." Materials Science and Technology 16: 26-40.

[18] Takeda, M., Mitome, M., Hayakawa, H., Nischiuchi, S., Tanabe, T., and Yamamoto, S. 2013. "Morphology and Crystallographic Phase of V-C Particles Formed in Fe-Cr-Ni-V-C Alloys." Materials Science and Technology 29 (6): 672-8. 